\title{
Antitumour effects and mechanisms of action of the panHER inhibitor, dacomitinib, alone and in combination with the STAT3 inhibitor, S3I-201, in human sarcoma cell lines
}

\author{
XIAOCHUN WANG ${ }^{1,2}$, DAVID GOLDSTEIN ${ }^{3}$, PHILIP J. CROWE ${ }^{1,2}$ and JIA-LIN YANG ${ }^{1,2}$ \\ ${ }^{1}$ Sarcoma and Nano-Oncology Group, Adult Cancer Program, Lowy Cancer Research Centre, and \\ Departments of ${ }^{2}$ Surgery and ${ }^{3}$ Medical Oncology, Prince of Wales Clinical School, \\ Faculty of Medicine, University of New South Wales, Sydney, NSW 2052, Australia
}

Received October 26, 2017; Accepted March 12, 2018

DOI: 10.3892/ijo.2018.4337

\begin{abstract}
The 5-year survival rate for metastatic sarcoma is $16 \%$. Although the phosphorylated human epidermal growth factor receptor (pEGFR/HER1) has been shown to be an independent predictor of overall survival in patients with sarcoma, we have previously demonstrated that sarcoma cell lines exhibit resistance, despite gefitinib blocking p-EGFR and signal transducers in EGFR downstream pathways. Gefitinib failed to decrease the ratio of phosphorylated (p-)signal transducer and activator of transcription (STAT3)/p-STAT1, suggesting that relative STAT3 abundance and activation may be involved in drug resistance. In this study, we used the panHER inhibitor, dacomitinib, to further block HER2-dependent activation, applying multiple methods, such as proliferation assay, clonogenic survival assay, anti-anoikis assay and western blot analysis. Although dacomitinib inhibited EGFR, HER2, AKT and Erk activation more effectively than gefitinib, it still only exerted minimal anti-proliferative effects on sarcoma cell lines due to the STAT3 escape pathway. However, the addition of the STAT3 inhibitor, S3I-201, to dacomitinib achieved a significant enhancement in growth inhibition, by perturbing p-STAT3/p-STAT1. Using a panel of sarcoma cell lines with different histological types, we identified that the addition of the STAT3 inhibitor enhanced the growth inhibitory effects of the panHER inhibitor, dacomitinib, on sarcoma cells. Our findings may have clinical implications on overcoming the resistance caused by the STAT3 escape pathway and optimising EGFR/panHER-targeted therapy in sarcoma.
\end{abstract}

Correspondence to: Professor Jia-Lin Yang, Room 209, Adult Cancer Program, Lowy Cancer Research Centre, University of New South Wales Sydney, 17 High Street, Kensington, NSW 2033, Australia E-mail: j.yang@unsw.edu.au

Key words: dacomitnib, panHER inhibitor, signal transducer and activator of transcription 3 , sarcoma, targeted therapy

\section{Introduction}

Sarcomas, including soft tissue sarcomas (STS) and osteosarcomas, are heterogeneous tumours that arise from transformed cells of mesenchymal origin, including malignant tumours made of bone, cartilage, fat, muscle, vascular or hematopoietic tissues. Patients with a localized sarcoma have a $83 \%$ chance for a 5-year survival, whereas those sarcomas with lymph node involvement have a reduced prognosis of $54 \%$ and the worst prognosis is $16 \%$ for sarcomas that have spread to distant parts of the body (1). This reflects the ineffectiveness of current therapy and the importance for the development of better treatment options to improve outcomes.

The human epidermal growth factor receptor (EGFR/HER) family of receptor tyrosine kinases, including EGFR/HER1/ ErbB1,HER2/ErbB2,HER3/ErbB3 and HER4/ErbB4,regulates proliferation, survival, adhesion, and the migration and invasion of malignant cells $(2,3)$. Following ligand binding to the extracelluar domain of HER family members, subsequent signalling cascades affect gene transcription through three downstream pathways: ras/raf/mitogen-activated protein kinase (MAPK), phosphoinositide 3-kinase (PI3K)/AKT and Janus kinase/signal transducer and activator of transcription (JAK)/signal transducer and activator of transcription (STAT) (4). Clinical studies have indicated that the hyperactivation of the HER family is associated with more aggressive diseases and poor clinical outcomes, so the HER family has been intensively pursued as therapeutic targets (5 and refs. therein).

We have previously reported that, in a cohort of 46 consecutive patients with STS, 78\% demonstrated a positive expression of EGFR (6). This finding is consistent with other series in STS with a mean of 68\% (range 60-77\%) (7-11). In a large Japanese study, EGFR expression was found to be significantly associated with the histological grade, but was not an independent prognostic factor for survival (7). Our recent studies demonstrated that EGFR and downstream signal transducers were highly expressed and activated in STS cell lines (12), and showed that phosphorylated (p-)EGFR p-EGFR) and p-Erk are independent prognostic factors for overall and/or cancer-specific survival in 87 STS samples (13). However, the specific EGFR inhibitor, gefitinib, was ineffective 
in terms of preclinical anti-proliferation, despite the inhibition of pEGFR and signalling transducers in the EGFR downstream PI3K/AKT and ras/raf/Erk MAPK pathways (12). Consistently, a phase II clinical trial demonstrated that single agent gefitinib was unsatisfactory with low response rates of 21 and $6 \%$ at 4 and 6 months, respectively and short disease control in advanced synovial sarcomas (14). All the above data suggest that novel approaches targeting this pathway are required in sarcoma.

Our previous study on gefitinib in sarcoma cell lines identified the STAT3 escape pathway as a potential resistance mechanism, due to the increased/unchanged ratio of pSTAT3/pSTAT1 from the JAK/STAT pathway (12). HER2 overexpression as an upstream regulator has been demonstrated to activate STAT3 and induce breast cancer growth $(15,16)$. In addition, HER2 also acts as a transcriptional co-activator of STAT3 and leads to cyclin D1 promoter activation to enhance tumour proliferation (17). Furthermore, blocking HER2 can induce apoptosis (18). These studies provide a rationale that HER2-induced STAT3 activation may be an escape pathway to EGFR-specific inhibition and suggest that a panHER inhibitor blocking both EGFR and HER2 may enhance the therapeutic effect.

Dacomitinib, a panHER inhibitor, has been shown to exert an irreversible inhibitory effect on the tyrosine kinase activation of human EGFR/HER1, HER2 and HER4, and is active in both EGFR-sensitive and EGFR-resistant preclinical models (19-23). Following initial phase I studies $(20,24,25)$, in subsequent phase II trials, it was shown to be well-tolerated and showed encouraging activity (25-27). In two phase II studies as a first-line therapy, dacomitinib demonstrated encouraging clinical activity in patients with recurrent and/or metastatic squamous cell cancer of the head and neck (SCCHN) and with clinically or molecularly selected advanced non-small cell lung cancer (NSCLC) (28-30). Although a randomised phase II trial demonstrated a significant improvement of progressionfree survival (PFS) (31), in two double-blind randomised phase III trials in patients pretreated with NSCLC, dacomitinib did not improve PFS/overall survival (OS) compared with the placebo or erlotinib in an unselected patient population $(32,33)$. However, a pooled subset analyses demonstrated that dacomitinib exhibited favourable trends in PFS for the EGFR activation mutation patient subgroup (34). Accordingly, dacomitinib is currently in a phase III study of first-line dacomitinib versus gefitinib in patients with advanced NSCLC harbouring activating EGFR mutations. Of note, in a recent interim analysis of the 452 patients in this study, dacomitinib treatment extended PFS and the duration of response versus gefitinib (35).

Considering the potential advantages of irreversible panHER inhibitors over their reversible counterparts, as well as our previous findings (12) that sarcoma cells exhibit resistance to gefitinib treatment through the STAT3 escape pathway, in this study, the panHER inhibitor, dacomitinib, was examined in sarcoma cell lines. We hypothesized that the use of dacomitinib would have the potential to increase the effectiveness of EGFR/HER1-targeted therapy in sarcomas by i) downregulating STAT3 via the inhibition of HER2 favouring an increased drive to apoptsis; ii) blocking EGFR/HER1 downstream ras/raf/MAPK and PI3K/AKT survival signals to further induce apoptosis; and iii) blocking other HER family member signalling to overcome resistance to single EGFR/HER1 inhibition. To date, no panHER inhibitor has been tested in sarcomas. The principal aim of this study was to investigate the in vitro antitumour effect and mechanisms of action of dacomitinib mono- and combination therapy in a panel of 13 human STS and osteosarcoma cell lines.

\section{Materials and methods}

Drugs and cell lines. The panHER inhibitor, dacomitinib (PF299804), was kindly provided by Pfizer USA (New York, NY, USA). The STAT3 inhibitor, S3I-201 (NSC74859), and the EGFR inhibitor, gefitinib, were purchased from Selleckchem (Scoresby, VIC, Australia) and Euroasian chemicals (Mumbai, India), respectively. The human sarcoma cell lines [SW872 (liposarcoma), HT1080 (fibrosarcoma), SW684 (fibrosarcoma), GCT (undifferentiated pleomorphic sarcoma), SW982 (synovial sarcoma), A431 (epidermoid carcinoma), SJSA (osteosarcoma), U2-OS (osteosarcoma), MG63 (osteosarcoma) and Saos-2 (osteosarcoma)] were purchased from the American Type Culture Collection (ATTC, Manassas, VA, USA). PC9 (lung adenocarcinoma) was purchased from Sigma-Aldrich (Castle Hill, NSW, Australia). The other cell lines [778 (fibrosarcoma), 449B (liposarcoma; also known as 93T449; STR profile available on ATCC, cat. no. ATCC CRL-3043), HOS (osteosarcoma) and 143B (osteosarcoma)] were kindly provided by Professor David Thomas (Peter MacCallum Cancer Centre, Melbourne, VIC, Australia) and Dr Florence Pedeatour (Nice University Hospital, Nice, France). The cell lines were all tested as mycoplasma-free, and were subjected to identification tests using short tandem repeat (STR) profiling by CellBank Australia (Westmead, NSW, Australia) and shown to be consistent with their stated cell lineage.

Cell culture and cell proliferation assay. All cells were maintained in Rosewell Park Memorial Institute (RPMI)-1640 medium, supplemented with $10 \%$ heat-inactivated fetal bovine serum (FBS), $2 \mathrm{mM}$ L-glutamine and antibiotics $(50 \mathrm{U} / \mathrm{ml}$ penicillin and $50 \mu \mathrm{g} / \mathrm{ml}$ streptomycin) at $37^{\circ} \mathrm{C}$ in a humidified $5 \% \mathrm{CO}_{2}$ and $95 \%$ atmosphere. Cell culture reagents were purchased from Gibco (Melbourne, VIC, Australia). Cells were grown as monolayer cultures in $75-\mathrm{cm}^{2}$ flasks. Once $80-90 \%$ confluent, the cells were detached with $0.05 \%$ trypsin-EDTA/PBS (Invitrogen, Carlsbad, CA, USA) and then cultured in a new flask for use in subsequent experiments. Cell proliferation assay was carried by crystal violet colorilmetric assay, as previously described (36). Briefly, $24 \mathrm{~h}$ after the cells were seeded, they were treated with the vehicle [dimethyl sulfoxide (DMSO), purchased from Amresco (Solon, OH, USA)] or drugs [including monotherapy with gefitinib, S3I-201, and dacomitinib, as well as combination therapy (refer to the Results section for the details of specific mono- or combination treatments, doses and treatment durations)]. At least duplicate experiments with each treatment group containing triplicate wells were carried out. After the required time period, the cells were washed with Dulbecco's phosphate-buffered saline (DPBS), stained with $0.5 \%$ crystal violet (Sigma-Aldrich) and incubated with elution solution 
(0.1 M sodium citrate and $100 \%$ ethanol), followed by light absorbance at $540 \mathrm{~nm}$ on a plate reader (Tecan; Grodig, Salzburg, Austria).

Clonogenic survival assay for adherent sarcoma cells. After $24 \mathrm{~h}$ of seeding, the cells were treated with the vehicle (DMSO) or drugs (200 nM of dacomitinib, $10 \mu \mathrm{M}$ of S3I-201 or $200 \mathrm{nM}$ of dacomitinib plus $10 \mu \mathrm{M}$ of S3I-201) and incubated at $37^{\circ} \mathrm{C}$. The drugs were present in the medium throughout the whole incubation period. Once colony-formation ( 1 colony $\geq 50$ cells, 6-8 days) was observed in the control wells, all related wells were washed and stained with crystal violet.

Anchorage-independent growth assay (anti-anoikis assay) by soft agar colony formation assay. The bottom gel was created by mixing $1 \%$ agarose with equivalent volume of $2 \mathrm{X}$ RPMI. Logarithmically growing cells were harvested and suspended in medium containing $0.35 \%$ soft agar. The cells were treated with the vehicle or the drugs in quadruplicate. Plates were maintained at $37^{\circ} \mathrm{C}$ in a humidified incubator for $1-2$ weeks until colonies were formed. Subsequently, $10 \%$ AlamarBlue (Invitrogen, Carlsbad, CA, USA) was added to each well and incubated for 4-20 h. The results were evaluated using a fluorescence microplate reader SpectrMax M3 (Molecular Devices, San Jose, CA, USA) with an excitation wavelength of $540-570 \mathrm{~nm}$ and an emission wavelength of 580-610 $\mathrm{nm}$.

Western blot analysis. The vehicle-treated and drug-treated cells were harvested, and total proteins were extracted and measured using western blot with $\beta$-actin as an internal protein loading control, with our standard procedures (37). Briefly, cells were starved overnight in RPMI-1640 medium containing $1 \%$ FBS and then treated with the vehicle (DMSO) or drugs $(200 \mathrm{nM}$ of dacomitinib and/or $20 \mu \mathrm{M}$ of S3I-201 for $24 \mathrm{~h}$ ). The cells were then harvested following $15 \mathrm{~min}$ of incubation with or without $100 \mathrm{ng} / \mathrm{ml}$ EGF stimulation, and total proteins were extracted using RIPA buffer (both from Sigma-Aldrich) with 1\% Protease and Phosphatase inhibitor cocktails (Merck, Bayswater, VIC, Australia). Protein concentrations were determined by BCA protein assay (Thermofisher, Scoresby, VIC, Australia), according to the manufacturer's instructions. Subsequently, $50 \mu \mathrm{g}$ proteins per lane were separated by 4-20\% SDS-PAGE and transferred onto nitrocellulose membranes (Bio-Rad, Gladesville, NSW, Australia), which were blocked with 5\% skim milk powder in TBS with 01\% Tween-20 (TBST) for $1 \mathrm{~h}$ at room temperature, and then probed with primary antibodies overnight at $4{ }^{\circ} \mathrm{C}$. The detection of $\beta$-actin was used to ensure equal loading and proper transfer of the protein. HRP-conjugated secondary antibodies were detected by chemiluminescence agent Supersignal Western Dura Extended Duration (Thermofisher). Membranes were imaged by ImageQuant LAS4000 (GE Healthcare; Silverwater, NSW, Australia). Densitometric analysis was performed by ImageQuant TL Software (GE Healthcare) and presented as ratios of protein expression normalized to relevant $\beta$-actin loading control. All antibodies (STAT antibody kit \#9939, p-STAT antibody kit \#9914, HER family antibody kit \#8339, PhosphoPlus AKT activation kit \#9280, MAPK family antibody kit \#9926, p-MAPK family antibody kit \#9910 and $\beta$-actin \#4970) were purchased from Cell Signaling
Technology (Arundel, QLD, Australia) and diluted as per the manufacturer's instructions.

Statistical analysis. Growth inhibition data were calculated using GraphPad Prism software, and $\mathrm{IC}_{50}$ curves were fitted using a non-linear regression model with a sigmoidal dose-response. Mean percentage growths in different treatment groups from at least duplicate experiments with triplicate samples against controls were analysed using ANOVA first. Significant differences obtained from ANOVA were further analysed by a post-hoc Bonferroni test. Two-tailed P-values $<0.05$ were considered to indicate statistically significant differences.

\section{Results}

Positive expression of HER1 and HER2 in sarcoma cell lines. We first examined HER1 expression in 13 sarcoma cell lines, using the PC9 cells as a positive control [which have been reported to express abnormally high levels of HER1 (38)]. The sarcoma cell lines expressed total HER1 (t-HER1) at a similar or higher level to that in the PC9 cells (Fig. 1) in the absence of ligand EGF stimulation. Phosphorylated HER1 (p-HER1) was undetectable in the Saos-2 and HOS cells, and was weakly expressed in the other sarcoma cell lines in the absence of EGF, while the PC9 cells exhibited a strong p-HER1 expression. We also found that EGF stimulation (closely mimicking the in vivo setting) induced p-HER1 expression in all 13 sarcoma cell lines, with the cells expressing lower (U2-OS, Saos-2 and HOS) or similar levels of p-HER1 compared with the PC9 cells. Similarly, with ligand EGF stimulation, 10/13 cell lines exhibited HER2 phosphorylation. In total, 6/7 STS (86\%) and $5 / 6$ osteosarcoma $(83 \%)$ cell lines expressed t-HER2 in the absence/presence of EGF.

Inhibition of the phosphorylation of HER family receptors and signalling factors in PI3K/AKT and ras/raf/MAPK pathways by dacomitinib monotherapy. Five sarcoma cell lines (3 STS and 2 osteosarcoma) were treated for $24 \mathrm{~h}$ with dacomitinib (PF299804) at its clinically achievable total plasma concentration (200 nM) (20). As shown in Fig. 2, dacomitinib markedly blocked EGF-induced p-HER1 expression in all 5 sarcoma cell lines, as well as that of p-HER2 in 4/5. In addition, dacomitinib decreased the activation of AKT and SAPK/JNK to baseline levels in all 5 sarcoma cell lines, and downregulated the the levels of p-Erk and p-p38 MAPK in 4/5 sarcoma cell lines, apart from p-Erk in the 143B cells and p-p38 in the 449B cells (Fig. 2).

Growth inhibitory effects of dacomitinib monotherapy on sarcoma cell lines. Following $72 \mathrm{~h}$ of treatment with 0.25-15 $\mu \mathrm{M}$ dacomitinib, the anti-proliferative ability was evaluated. The $\mathrm{IC}_{50}$ values are summarized in Table I. At the early time point ( $72 \mathrm{~h}$ of treatment), all the cell lines exhibited a greater sensitivity to dacomitinib [ $\mathrm{IC}_{50}$ values: $1-5 \mu \mathrm{M}$ for dacomitinib versus $14-30 \mu \mathrm{M}$ for gefitinib in our previous study on gefitinib (12)]. However, the $\mathrm{IC}_{50}$ values of dacomitinib in the sarcoma cell lines were still 1,000-fold higher than those in the sensitive control cell line, PC9 $(1 \mathrm{nM})$. Extending the treatment window for longer time period of up to 7 days, we found that all the cell lines exhibited further growth inhibitory 


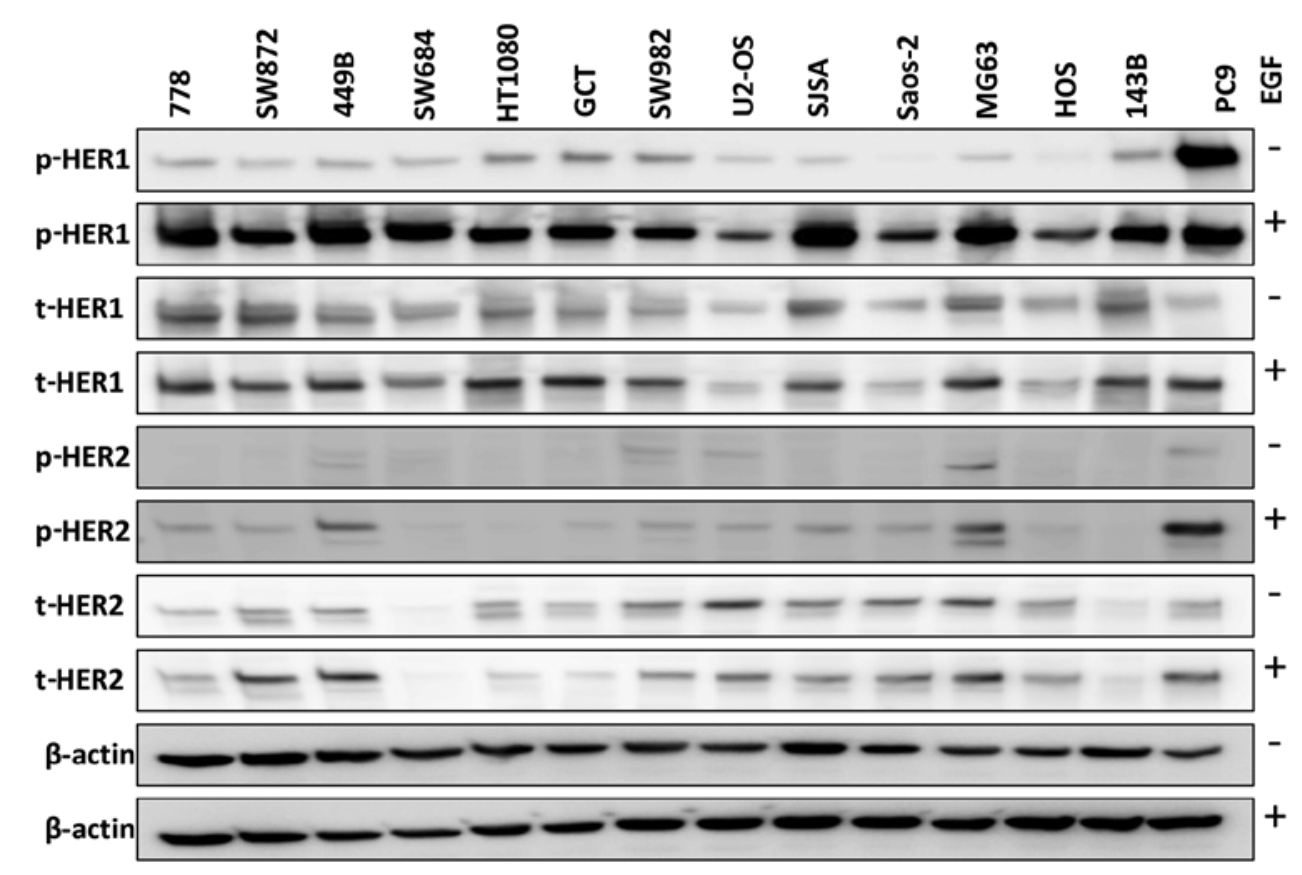

Figure 1. Expression of HER family receptors in a panel of sarcoma cell lines. Basal phosphorylated (p-) and total (t-) HER1 and HER2 levels were detected by western blot analysis (at least 2 independent experiments) in 7 soft tissue sarcoma and 6 osteosarcoma cell lines without or with ligand (100 ng/ml EGF for $15 \mathrm{~min}$ ) stimulation. PC9 (lung cancer cell line) served as a positive control.

effects. The $\mathrm{IC}_{50}$ values for the 778, 449B, Saos-2 and SW684 cells were 3- to 5-fold lower than those on day 3. In particular, the $\mathrm{IC}_{50}$ values for 6 sarcoma cell lines were scaled down to $<1 \mu \mathrm{M}$.

In addition, clonogenic survival assay was also performed to determine the long-term effects of dacomitinib on the sarcoma cell lines. Dacomitinib at the concentration of $<1.4 \mu \mathrm{M}$ suppressed colony formation by $50 \%$ in the sarcoma cell lines, with $\mathrm{IC}_{50}$ values of 0.163 and $0.184 \mu \mathrm{M}$ for the SW982 and 143B cells, respectively, which were higher than those of the sensitive control cell line, $\mathrm{A} 431\left(\mathrm{IC}_{50}, 0.044 \mu \mathrm{M}\right)$, treated with dacomitinib (Table I).

The STAT3 escape pathway and the resistance of dacomitinib monotherapy in sarcoma. Although dacomitinib markedly inactivated HER family members and downstream ras/raf/MAPK and PI3K/AKT pathways, it failed to supress sarcoma cell growth and colony formation at reasonable $\mathrm{IC}_{50}$ values, compared with the sensitive control. The increased or unaltered ratio of p-STAT3/p-STAT1 was found to be associated with the STAT3 escape pathway in our previous study on the EGFR inhibitor, gefitinib, in sarcoma cell lines (12). In the present study, we found that dacomitinib inhibited p-STAT1 expression in 4/5 sarcoma cell lines by $97,62,41$ and 33 in the 778, HOS, 449B and 143B cells, respectively, compared with the corresponding vehicle control in the presence of EGF stimulation (Fig. 3A). However, the effects of dacomitinib on p-STAT3 expression were highly variable: We observed a decreased p-STAT3 expression in the 143B cells (27\%) and 778 cells ( $47 \%$ ); however, p-STAT3 expression was unaltered in the HOS cells and it increased in the 449B cells (1.8-fold) and SW872 (2.1-fold) (Fig. 3B). The ratio of p-STAT3/p-STAT1 was increased in $3 / 5$ cell lines (HOS, 449B and 778 cells) and unaltered in the 143B and SW872 cells (Fig. 3C), suggesting that the STAT3 relative abundance and activation likely plays an important role in sarcoma growth, maintenance and resistance mechanisms.

Enhancement of the sensitivity of sarcoma cells to dacomitinib by the STAT3 inhibitor, S3I-201. A panel of 7 STS and 2 osteosarcoma (HOS and 143B) cell lines were treated with the vehicle, dacomitinib, or S3I-201, or a combination of dacomitinib and S3I-201 at 3 concentrations (lower than the clinically achievable total plasma concentration $200 \mathrm{nM}$ ) in the constant ratio (dose ratio of dacomitinib to S3I-201 $=1: 100$ ). At 7 days post-administration, in 7/9 cell lines, combination therapy achieved significantly enhanced anti-proliferative effects (Fig. 4A). The HOS cells, which were the most sensitive (almost 100\%) to S3I-201 monotherapy, did not exhibit any further growth inhibition. We also examined combination therapy in the S3I-201-resistant SW872 cells (36) and found that these cells did not undergo any further enhancement of the growth inhibitory effects. Dacomitinib is $\sim 98 \%$ bound to plasma proteins in human plasma, as measured by equilibrium dialysis (kindly suggested by Dr Scott Weinrich, Director of Early Clinical Development, Pfizer USA). This indicates that only $2 \%$ constitutes the 'free' drug in the circulation of patients; therefore, the $200 \mathrm{nM}$ total plasma concentration becomes $4 \mathrm{nM}$ 'free' drug. Considering that it should be the 'free' drug concentration at the site of action that exerts the biological activity (39), we aimed to emulate clinical exposure in vitro by the addition of up to $4 \mathrm{nM}$ dacomitinib to the most sensitive cell line, 778 . This achieved a significantly enhanced anti-proliferative effect (combination versus dacomitinib: $\mathrm{P}=0.003$; combination versus S3I-201: $\mathrm{P}=0.0002$ ) (Fig. 4B).

In addition, clonogenic assay was performed on the 778, 143B and SW872 cells, representing a sensitive STS cell line, a sensitive osteosarcoma cell line and a resistant cell line, 
A
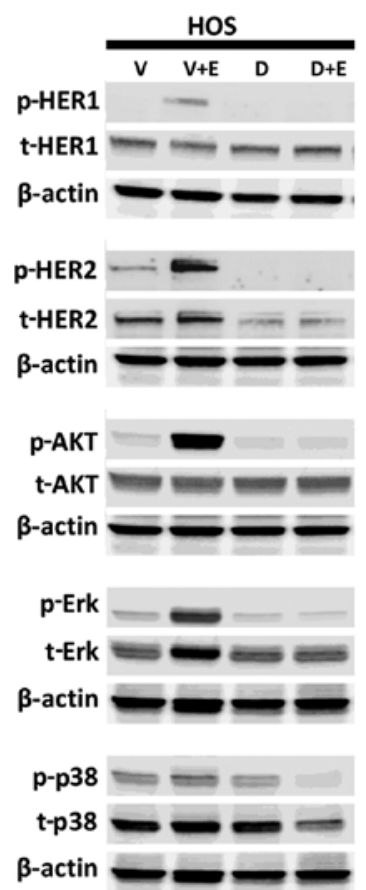


$\longrightarrow$
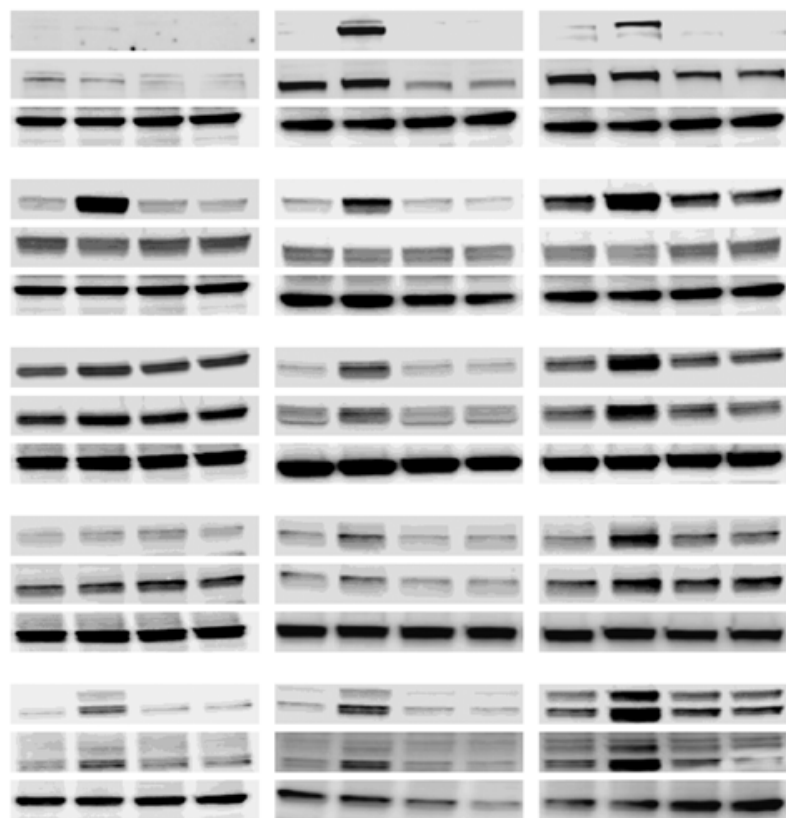

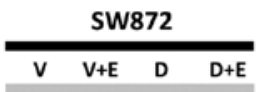

\begin{tabular}{llll}
\multicolumn{4}{c}{778} \\
\hline$V$ & $V+E$ & $D$ & $D+E$
\end{tabular}



$\Leftrightarrow=$

$\rightarrow-\infty$
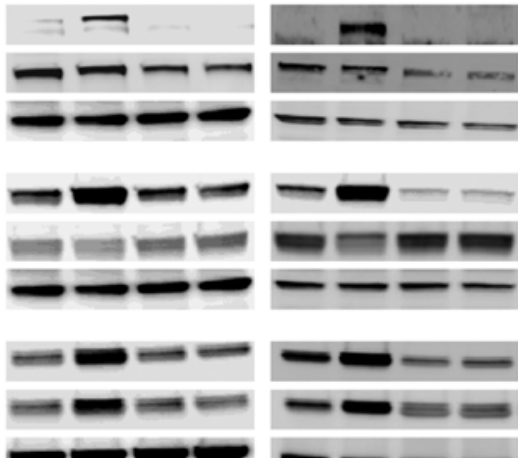

$\longrightarrow$

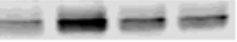

$\rightarrow$

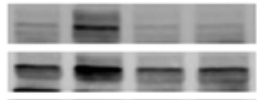

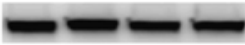
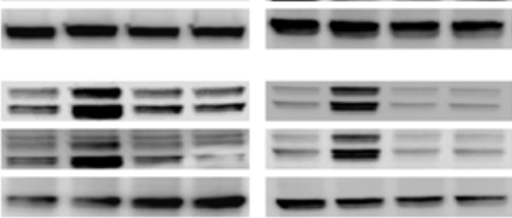

B
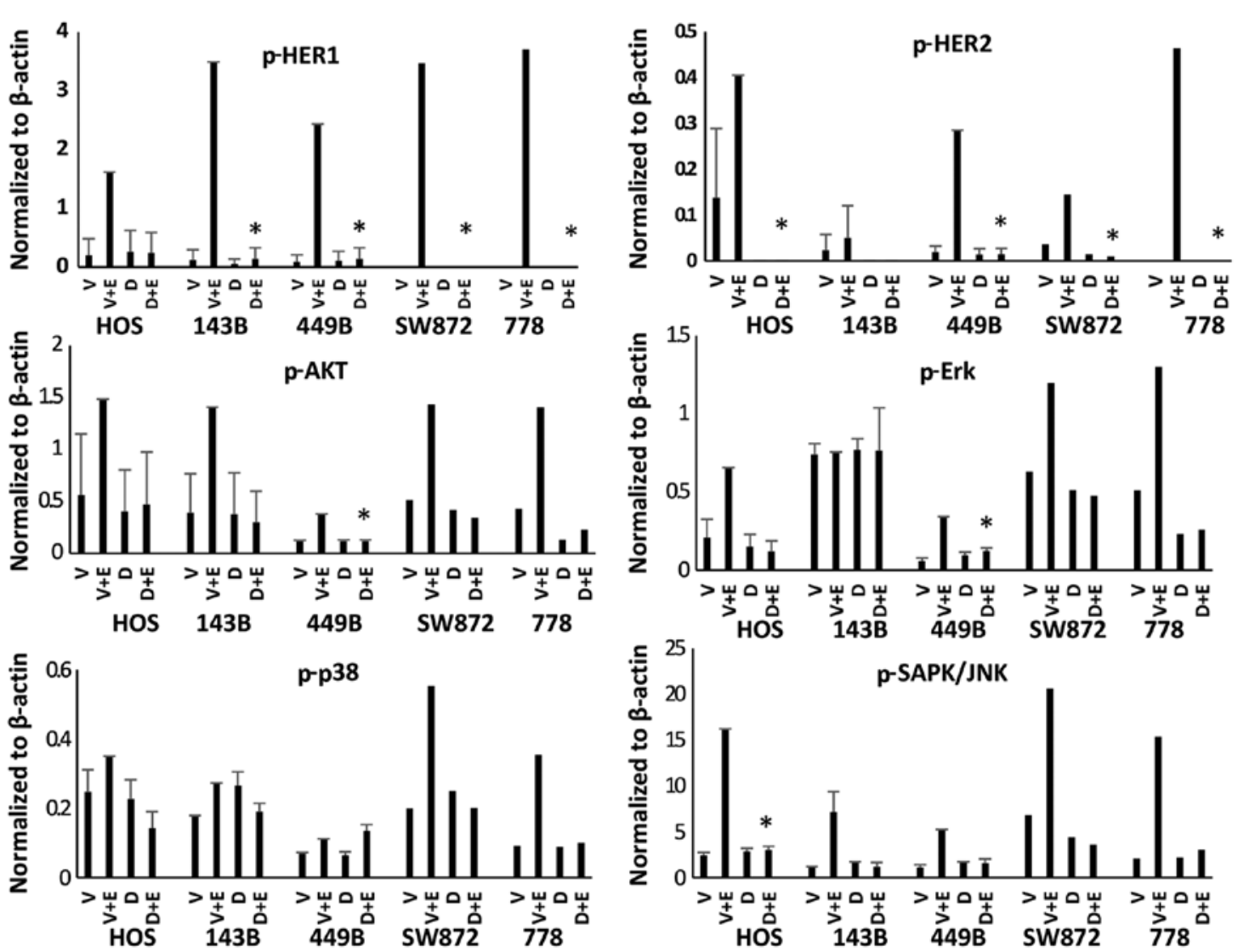

Figure 2. Dacomitinib (PF299804) decreased the phosphorylation (activity) of the HER family receptors (HER1 and HER2), as well as signalling factors in the PI3K/AKT and ras/raf/MAPK downstream pathways (AKT, Erk, p38 MAPK and SAPK/JNK). A panel of 5 sarcoma cell lines (HOS, 143B, 449B, SW872 and 778) were treated with $200 \mathrm{nM}$ of dacomitinib for $24 \mathrm{~h}$, followed by incubation with or without EGF for 15 min, and the the extracted proteins were then immunoblotted with the indicated phosphor-specific antibodies. Membranes used for analysis of phosphorylated proteins were stripped and reblotted with the respective total antibodies. The expression of $\beta$-actin was analysed from the same cell lines as a loading control. $\mathrm{V}$, vehicle control; $\mathrm{V}+\mathrm{E}$, vehicle control plus EGF stimulation; D, $200 \mathrm{nM}$ dacomitinib treatment; D+E, $200 \mathrm{nM}$ dacomitinib treatment plus EGF stimulation. (A) Representative western blot images. (B) Expression levels of the indicated proteins were quantified by densitometry and normalized to $\beta$-actin loading control. P-values (D+E vs. V+E) $<0.05$ were considered statistically significant. ${ }^{*} \mathrm{P}<0.05$. 
A

HOS



$143 B$

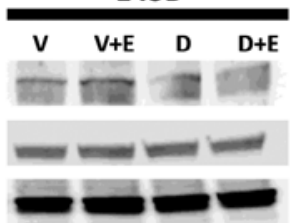

449B

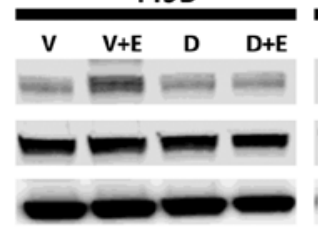

SW872

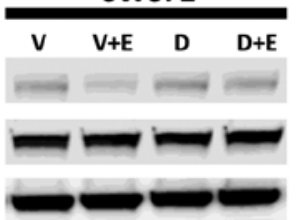

778

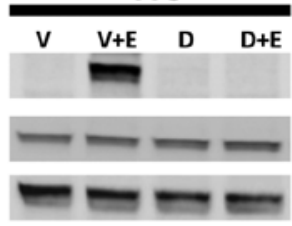

449B
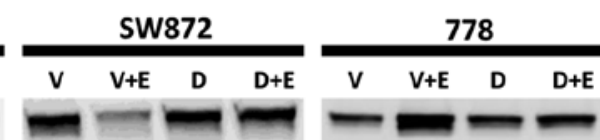

C

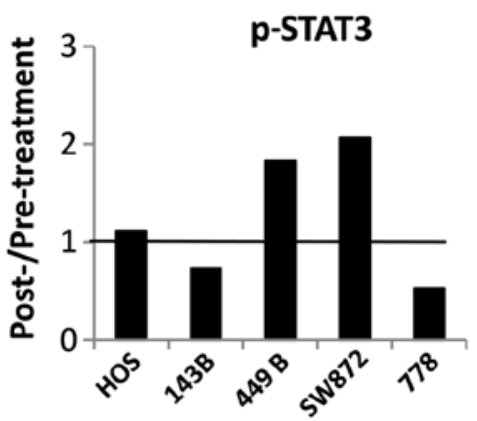

143B

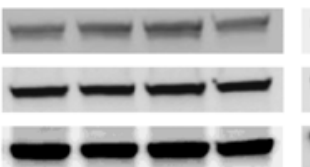

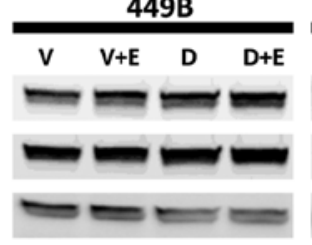



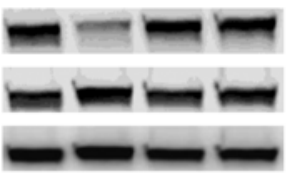
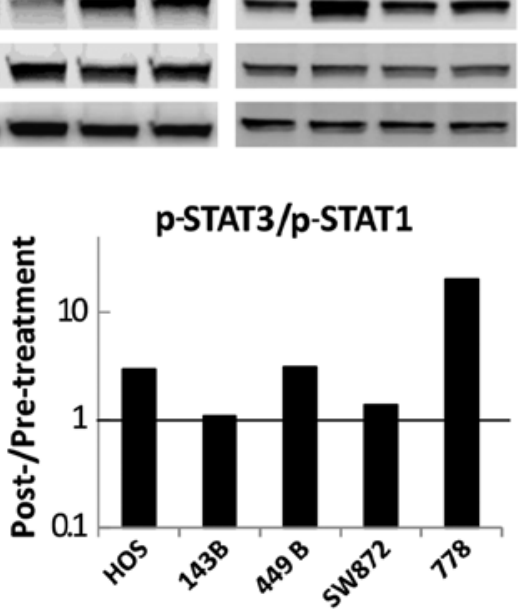

Figure 3. Expression of both phosphorylated and total (A) STAT1 and (B) STAT3 before and after dacomitinib (PF299804) treatment in osteosarcoma and soft tissue sarcoma cell lines. Five sarcoma cell lines were treated with the vehicle (DMSO) or $200 \mathrm{nM}$ dacomitinib for $24 \mathrm{~h}$, and were then harvested for western blot analysis against (A) STAT1 and (B) STAT3. (C) Corresponding bar charts show the protein alterations (p-STAT3, p-STAT1 and p-STAT3/p-STAT1) followed by dacomitinib treatment in the presence of EGF stimulation. The density of proteins was quantified using Quantity One analysis software and presented as relative expression to the vehicle control (post-/pre-treatment). V, vehicle control; V+E, vehicle control plus EGF stimulation; D, $200 \mathrm{nM}$ dacomitinib treatment; D+E, $200 \mathrm{nM}$ dacomitinib treatment plus EGF stimulation.

Table I. $\mathrm{IC}_{50}$ values of dacomitinib in 13 sarcoma cell lines.

\begin{tabular}{lccc}
\hline & \multicolumn{2}{c}{ Anti-proliferation } & \\
\cline { 2 - 3 } & $\begin{array}{c}\mathrm{IC}_{50} \text { value on } \\
\text { day } 3(\mu \mathrm{M})\end{array}$ & $\begin{array}{c}\mathrm{IC}_{50} \text { value on } \\
\text { day } 7(\mu \mathrm{M})\end{array}$ & $\begin{array}{c}\mathrm{IC}_{50} \text { of anti-colony } \\
\text { formation }(\mu \mathrm{M})\end{array}$ \\
\hline 449B & $4.4 \pm 0.8$ & $1.3 \pm 0.3$ & $0.677 \pm 0.057$ \\
778 & $3.1 \pm 0.9$ & $0.9 \pm 0.2$ & $1.326 \pm 0.032$ \\
GCT & $2.2 \pm 0.1$ & $1.3 \pm 0.1$ & $1.142 \pm 0.027$ \\
HT1080 & $2.2 \pm 0.5$ & $0.9 \pm 0.2$ & $0.781 \pm 0.058$ \\
SW684 & $5.6 \pm 1.3$ & $1.1 \pm 0.2$ & No colonies formed \\
SW872 & $3.7 \pm 0.6$ & $1.6 \pm 0.3$ & $0.875 \pm 0.089$ \\
SW982 & $2.0 \pm 0.3$ & $0.8 \pm 0.2$ & $0.163 \pm 0.055$ \\
SJSA & $3.9 \pm 1.3$ & $1.5 \pm 0$ & No colonies formed \\
U2-OS & $3.7 \pm 1.5$ & $0.5 \pm 0$ & $0.278 \pm 0.083$ \\
143B & $4.6 \pm 0.1$ & $2.4 \pm 0.1$ & 0.184 \\
HOS & $3.6 \pm 1.0$ & $1.3 \pm 0.5$ & $0.455 \pm 0.033$ \\
MG63 & $2.3 \pm 0.6$ & $1.0 \pm 0$ & No colonies formed \\
Saos-2 & $1.9 \pm 0.3$ & $0.6 \pm 0.1$ & No colonies formed \\
PC-9 (serving as & 0.001 & -- & -- \\
sensitive control) & & & 0.044 \\
A431 (serving as & -- & -- & \\
sensitive control) & & & \\
\hline
\end{tabular}

respectively, to further examine the cell responses to the combination therapy. Consistently, the 778 and 143B cells exhibited an enhanced inhibition of their colony-forming ability (Fig. 5), whereas the SW872 cells were still resistant to both monotherapies and combination therapy.

Enhancement of anoikis by dacomitinib and S3I-201 in sarcoma cell lines. Anchorage-independent growth (the ability to evade anoikis) using the 3D soft agar colony formation assay was then applied to assess cancer metastatic (anoikis-resistance) ability in sarcoma cell lines following treatment with dacomitinib and S3I-201 monotherapy or their combination. The results shown in Fig. 6 confirmed that combination therapy markedly enhanced anoikis (apoptosis occurred when the cells detached to the extracellular matrix) in the 778, 449B and 143B cells. However, this enhancement was not observed in the HOS cells, in which the combination therapy did not further enhance anoikis compared to treatment with S3I-201 alone treatment, no in the SW872 cells, in which all treatments (both drug mono- and combinationtherapies) did not restore anoikis.

Contribution of the downregulation of STAT3 phosphorylation to the enhanced effects observed with combination therapy. Using different methods (crystal violet colorimetric, clonogenic and anoikis assays), we demonstrated that combination treatment with S3I-201 enhanced the sensitivity to dacomitinib in the sarcoma cell lines. As a preliminary investigation of the potential mechanisms of action behind the enhancement, western blot analysis was performed on 3 sarcoma cell lines, representing a strong enhancement (778 cells), moderate 
A



SW982

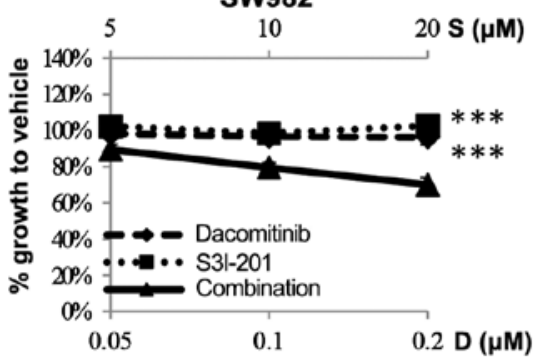

SW872

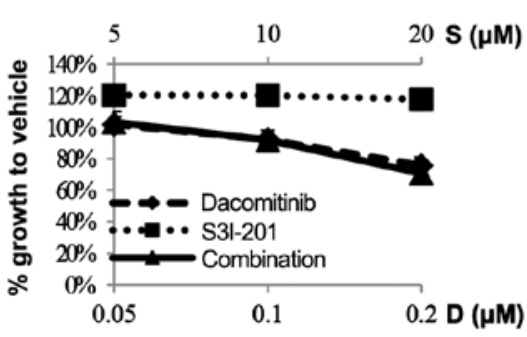

B

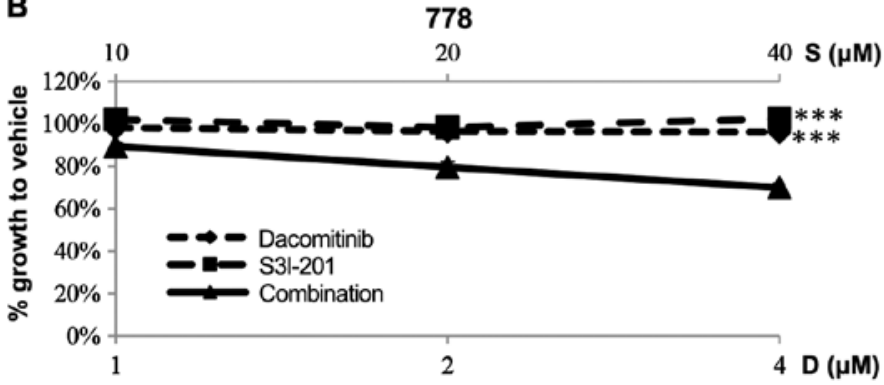

449B

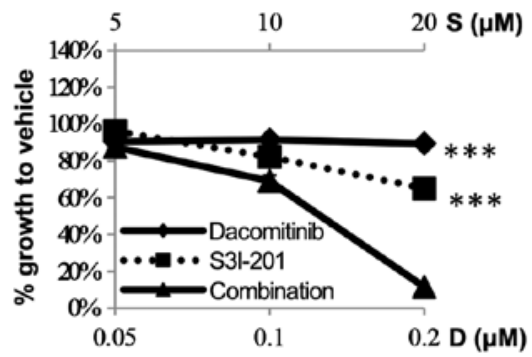

SW684

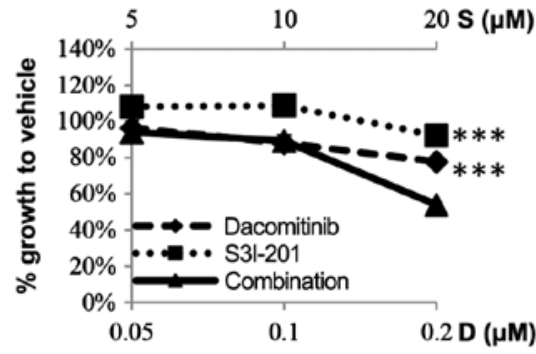

143B

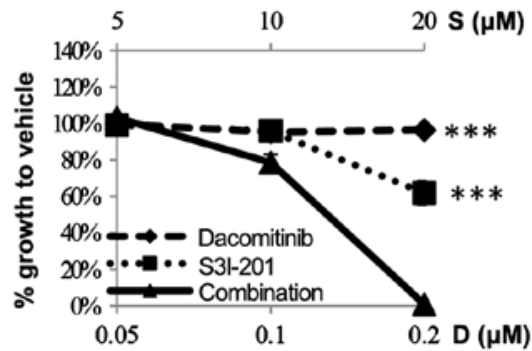

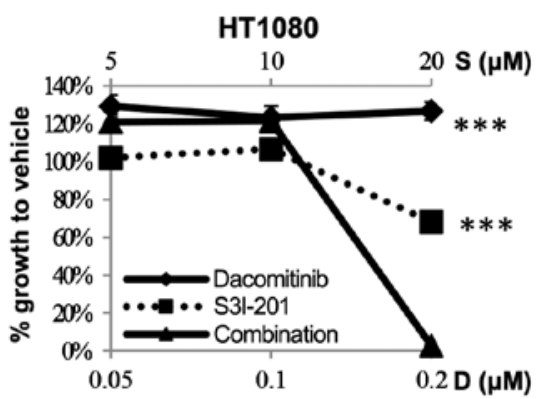

GCT

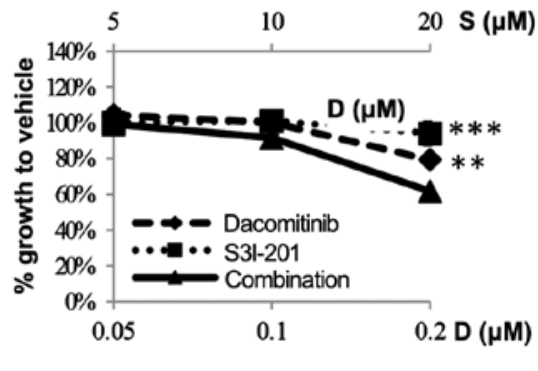

HOS



Figure 4. Growth inhibition curves following mono- or combination therapy using dacomitinib and S3I-201 in 7 soft tissue sarcoma and 2 osteosarcoma cell lines. The cells were seeded into 96-well plates, followed by a 7-day treatment with the vehicle, dacomitinib alone, S3I-201 alone or combination of both drugs. The concentrations of both drugs were (A) 5, 10 or $20 \mu \mathrm{M}$ for S3I-201 and 0.05, 0.1 or $0.2 \mu \mathrm{M}$ for dacomitinib; and (B) 10 , 20 or 40 $\mu \mathrm{M}$ for S3I-201 and 1,2 or $4 \mathrm{nM}$ for dacomitinib. Cell viability was determined by the crystal violet colorimetric assay and the vehicle (DMSO)-treated cells were considered as $100 \%$. Data in the diagram represent the means \pm SEM (standard error of the mean) from at least duplicate independent experiments with triplicate samples within each experiment. There are two x-sxes: top for S3I-201 (S) and bottom for dacomitinib (D). P-values (combination therapy versus dacomitinib/S3I-201 monotherapy) $<0.05$ were considered statistically significant. ${ }^{* *} \mathrm{P}<0.01 ;{ }^{* * * *} \mathrm{P}<0.001$.

enhancement (449B cells) and resistance (SW872 cells). In the 778 cells, treatment with S3I-201 alone downregulated constitutive STAT3 phosphorylation; however, the blockage of p-STAT3 was partially recovered by EGF stimulation. As expected, the combination therapy induced almost complete (94\%) inhibition of STAT3 phosphorylation, even with EGF stimulation (Fig. 7). In the 449B cells, the addition of $200 \mathrm{nM}$ dacomitinib also led to the further blockage of STAT3 phosphorylation compared to treatment with S3I-201 alone (from 77 to 90\%). However, in the SW872 cells, which exhibited resistance to both monotherapies and combination treatment in our anti-proliferation assay, combination therapy did not effectively inhibit STAT3 phosphorylation, as shown by the results of western blot analysis (Fig. 7).

Comparison of panHER inhibition with HER1 in combination with STAT3 inhibition. Previously, we reported that the addition of the STAT3 inhibitor, S3I-201, to the EGFR inhibitor, gefitinib, achieved synergistic anti-proliferative and pro-apoptotic effects in sarcoma cell lines (12). In this study, to compare the potential effects of concurrent inhibition using dacomitinibS3I-201 with previous gefitinib-S3I-201, we examined the growth-inhibiting ability of the combination therapies at the clinically achievable concentrations for each drug $(10 \mu \mathrm{M}$ for 

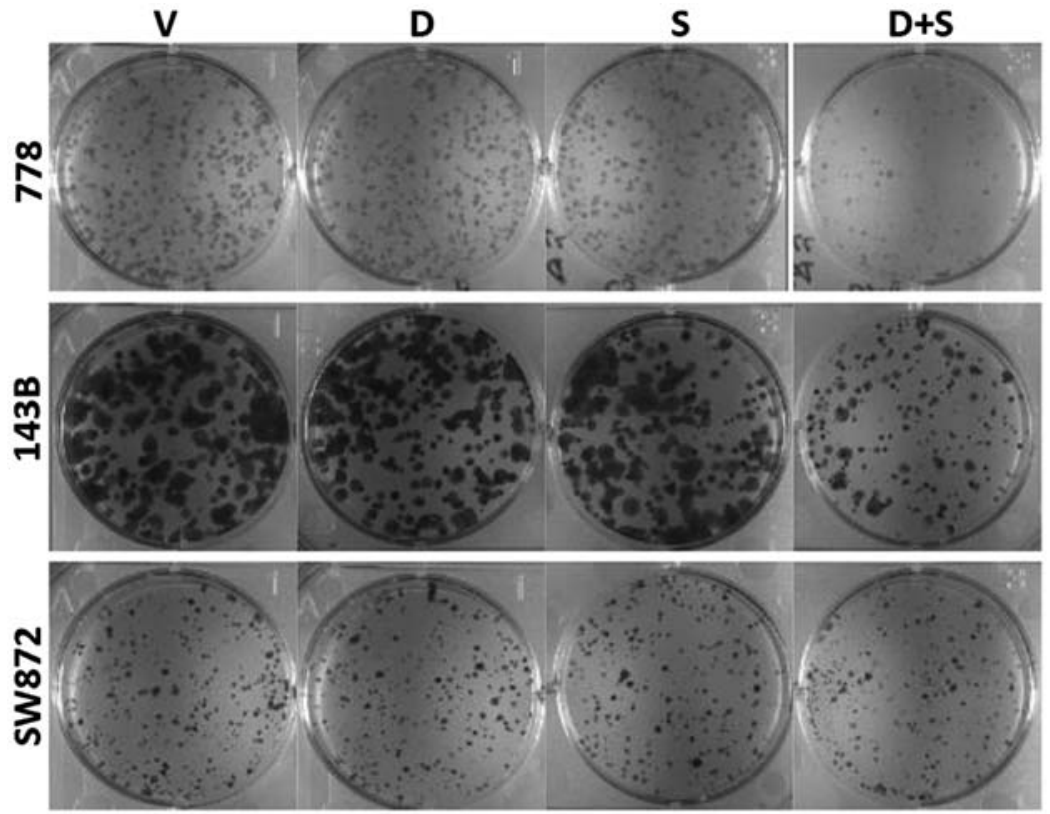

Figure 5. Clonogenic assay following mono- or combination therapy using dacomitinib and S3I-201 in 778, 143B and SW872. Representative wells from duplicate samples are shown for different treatment with V (vehicle control, DMSO), D (dacomitinib), S (S3I-201) and D+S (combination therapy using dacomitinib and S3I-201) in the 778, 143B and SW872 cells.


Figure 6. Anti-colony formation ability in 3D soft agar coated 96-well plate following combination therapy using dacomitinib (PF299804) and S3I-201 in 5 sarcoma cell lines. The cells, growing in medium containing 0.35\% soft agar (above 0.5\% agar), were treated by vehicle (DMSO), dacomitinib (PF299804), S3I-201 or combination. Plates were incubated for 1-2 weeks until colonies were formed. The cells were stained with AlamarBlue and then evaluated using a fluorescence microplate reader.

gefitinib and $200 \mathrm{nM}$ for dacomitinib) at the same time (Fig. 8). After $24 \mathrm{~h}$ of seeding, the HT1080 cells were treated with the vehicle (DMSO), S3I-201, gefitinib, dacomitinib, gefitinib plus
S3I-201 or dacomitinib plus S3I-201 for 3 or 7 days. In terms of combination versus monotherapy with dacomitinib or gefitinib, treatment with dacomitinib led to a similar P-value (0.024) as 
A



B



C

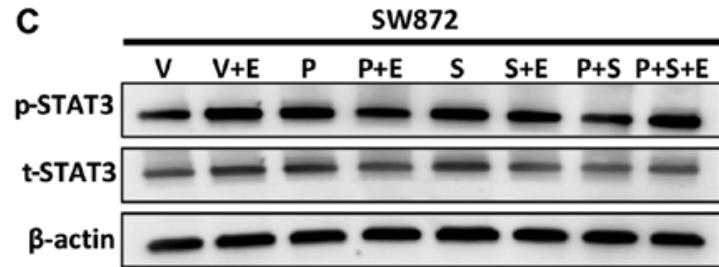

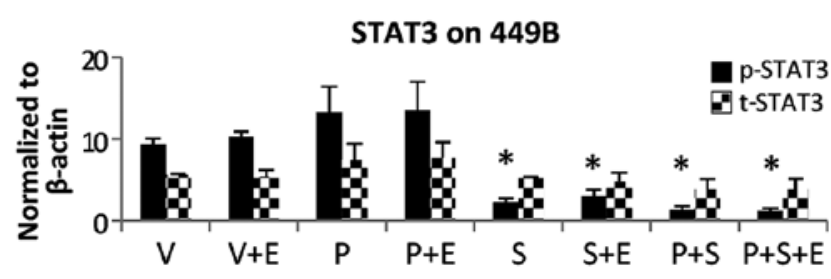


Figure 7. The expression of phosphorylated and total STAT3 in sarcoma cell lines (449B, 778 and SW872) treated with V (vehicle control), P (panHER inhibitor dacomitinib), S (S3I-201) and P+S (combination therapy) with or without E (EGF) stimulation. The starved cells were initially treated with the drug(s) or vehicle for $24 \mathrm{~h}$, followed by $15 \mathrm{~min}$ of EGF stimulation or not. The cell lysate was subject to western blot analysis. (A1, B1 and C1) Representative western blot images. (A2, B2 and C2) Expression levels of the indicated proteins were quantified by densitometry and normalized to $\beta$-actin loading control. P-values (compared to the vehicle) $<0.05$ were considered statistically significant. ${ }^{*} \mathrm{P}<0.05$.

A

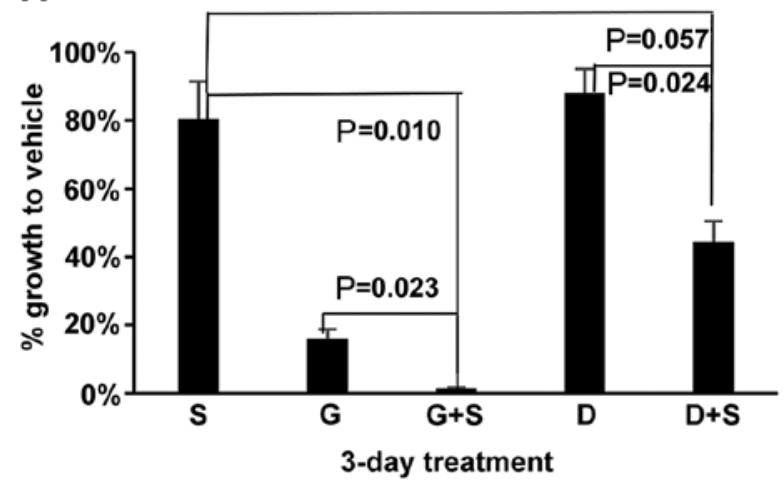

B



Figure 8. Anti-proliferative effects of the combination therapy using S3I-201 and gefitinib/dacomitinib. The HT1080 cells were seeded into 96-well plates, followed by a 3-day (A) or 7-day (B) treatment with vehicle, S (S3I-201, $20 \mu \mathrm{M})$, G (gefitinib, $10 \mu \mathrm{M})$, D (dacomitinib, 200 nM), G+S (gefitinib-S3I-201) or $\mathrm{D}+\mathrm{S}$ (dacomitinib-S3I-201). Data in the diagram represent the means \pm SEM (standard error of the mean) from at least duplicate independent experiments with triplicate samples within each experiment.

gefitinib (0.023) after 3 days of treatment, and to an even lower P-value (0.004) than gefitinib (0.079) after 7 days of treatment. The combination treatment with dacomitinib and S3I-201 (56 and 65\% growth inhibition on days 3 and 7, respectively) significantly enhanced the anti-proliferative effects compared to dacomitinib monotherapy; however, it exerted less potent inhibitory effects than gefitinib-S3I-201 (98 and 99\% inhibition) on sarcoma cell growth.

\section{Discussion}

In this study, we discovered that apart from EGFR/HER1, another HER family receptor, HER2, was also overexpressed in human sarcoma cell lines. The panHER inhibitor, dacomitinib, successfully inhibited the activation of HER family members (p-EGFR and p-HER2), as well as HER downstream pathway signalling transducers (p-AKT, p-Erk, p-p38 MAPK and $\mathrm{p}$-SAPK/JNK). Despite the suppression of these pathways, the results of cell proliferation and colony formation assay revealed that all 13 sarcoma cell lines were insensitive to dacomitinib. We demonstrated that dacomitinib increased or did not significantly alter the ratio of oncogene p-STAT3 versus tumour suppressor p-STAT1, indicating that STAT3 may represent an escape pathway that correlates with the resistance of sarcoma cell lines to dacomitinib. To conclusively determine causation will require additional studies with siRNA and/or transgenic 
mouse models in the future. This mechanism (the STAT3 escape pathway), if further validated, may prove to be a targetable mechanism of resistance to EGFR blockade in sarcoma.

Even though the overexpression of p-EGFR and its downstream signal transducers is noted in sarcoma tissues and cell lines and is negatively associated with sarcoma outcomes, we have shown a limited inhibitory effect of EGFR pathway blockade using the specific EGFR inhibitor, gefitinib, due to the relative activation of STAT3 (12). The observation of HER2-positive expression in sarcoma cell lines indicated that the blockade of a single receptor of the HER family may be compromised by signalling through other members. HER2 overexpression has been demonstrated to activate STAT3 and to act as a transcriptional co-activator of STAT3 and contribute to tumour initiation and growth (15-17). The activation of HER 2 signalling has been reported to be associated with the primary resistance of metastatic colorectal carcinoma to EGFR-targeted therapy (40). In addition, MET amplification/ overexpression has also been reported to promote resistance to gefitinib by driving the HER3-dependent activation of PI3K in a gefitinib-sensitive lung cancer cell line (HCC827) $(41,42)$. Therefore, we hypothesized that targeting all HER family members using a panHER inhibitor may enhance the inhibitory effects of targeted therapy in sarcoma. Dacomitinib is a highly effective panHER inhibitor both in vitro and in vivo in a broad range of human cancer cell lines (21-23,43-45).

In this study, we demonstrated that dacomitinib markedly suppressed the activation of both EGFR/HER1 and HER2, as well as their representative downstream signalling factors in ras/raf/MAPK and PI3K/AKT pathways, including p-AKT, p-Erk, p-p38 and p-SAPK/JNK. This was consistent with the findings of other studies on breast cancer and head and neck squamous cell carcinoma cell lines $(44,45)$. Despite this, the anti-proliferative effect of dacomitinib in our study indicated that all 13 sarcoma cell lines were resistant to the drug with $\mathrm{IC}_{50}$ values of $\sim 1 \mu \mathrm{M}$, greater than that of our sensitive control lung cancer cell line, PC9 $(1 \mathrm{nM})$, which is similar to previous reports on non-sarcoma cell lines $(21,46)$. The results of western blot analysis revealed that dacomitinib did not decrease the ratio of p-STAT3/p-STAT1. Dacomitinib, despite its additional blockade of HER 2 compared with gefitinib blocking HER1 only, showed lower $\mathrm{IC}_{50}$ values, but no improvement in biologically and potentially clinically meaningful antitumour effects. Rather than the EGF pathway not being relevant to tumour promotion in sarcoma, this absence of benefit appears to be a result of failure to overcome the STAT3 escape pathway, which may be regulated by HER-independent upstream mediators. In head and neck squamous cell carcinoma and lung adenocarcinomas, STAT3 constitutive activation has been reported to use an autocrine/paracrine-activating loop through alternative pathways, such as IL-6/gp130 $(47,48)$. HER-independent JAK/STAT3 (such as IL-6/JAK/STAT3) leads to the ineffectiveness of targeting HER family pathway. STAT3 is a more downstream point of convergence in many ligand/receptor pathways (such as growth factor and cytokine receptors) and non-receptor tyrosine kinase pathways (such as Src) and consequently cross-talk among these signalling pathways may contribute to resistance to EGFR/panHER inhibitors (49).

In this study, we found that the addition of S3I-201 to dacomitinib induced significant enhancement of the anti-proliferative effects (7/9 cell lines), further inhibited colony formation ( $2 / 3$ cell lines) and enhanced anoikis ( $3 / 5$ of sarcoma cell lines). Our preliminary STAT3 expression and regulation analysis revealed the additional inactivation of STAT3 by the combination treatment in sensitive sarcoma cell lines. By contrast, in the SW872 liposarcoma cell line, which exhibited resistance to the combination therapy in the anti-proliferation assay, STAT3 activation was not inhibited by the combination treatment. Comparing the current dacomitinib-S3I-201 combination with the one in our previous study (gefitinib-S3I-201) (13), we found that dacomitinib-S3I-201 did not demonstrate superior anti-proliferative activities.

Consistent with our findings, the activation of JAK/STAT3 signalling pathway mediated by autocrine and paracrine IL-6R has been found to be associated with the development of drug resistance to the irreversible panHER inhibitors, dacomitinib and afatinib in non-small cell lung cancer (50). The blockade of the IL-6R/JAK/STAT3 signalling pathway significantly enhanced the sensitivity to these irreversible inhibitors in both in vitro and in vivo models. Taken together, these results of STAT inhibition used to overcome primary resistance to EGFR blockade encourage the further exploration of this approach. Further experiments will require optimisation through nextgeneration inhibitors, different drug ratios, and the sequence of drug administration in vitro, followed by assessing the effectiveness and safety of combination therapy using both panHER and STAT3 inhibitors in vivo in sarcoma animal models.

We thus conclude that neither the first-generation reversible specific EGFR inhibitor, gefitinib, nor the second-generation irreversible panHER inhibitor, dacomitinib, as single agents are likely to have clinical utility in sarcoma. The relative abundance and activation of STAT3 may be involved in the resistance mechanism in both EGFR- and panHR-targeted therapies. To the best of our knowledge, our results are the first to demonstrate the significantly and highly anti-proliferative effects of the combination of the irreversible panHER inhibitor, dacomitinib, and the STAT3 inhibitior, S3I-201, in sarcoma cell lines. These results provide a rationale for further in vitro and in vivo studies inhibiting both EGFR/panHER and STAT3 in combination for the treatment of sarcoma.

\section{Acknowledgements}

Not applicable.

\section{Funding}

This study was supported by the Pfizer USA (grant no. IIR \#WS1914693). XW was awarded Rainbows for Kate PhD Scholarship from the Australasian Sarcoma Study Group.

\section{Availability of data and materials}

The analysed datasets generated during the study are available from the corresponding author on reasonable request.

\section{Authors' contributions}

$\mathrm{XW}$ contributed to performing the experiments, data acquisition and analysis and manuscript drafting. JLY contributed to 
Pfizer IIR grant application, project design, supervision, grant management, statistical analysis and manuscript revision. DG and PJC assisted in the study design and conception and revised the manuscript. All authors have read and approved the final manuscript.

\section{Ethics approval and consent to participate}

Not applicable.

\section{Consent for publication}

Not applicable.

\section{Competing interests}

The authors declare that they have no competing interests.

\section{References}

1. Sarcoma, Soft Tissue: Statistics. ASCO, Cancer.Net Editorial Board, 2016. http://www.cancer.net/cancer-types/sarcoma-softtissue/statistics.

2. Baselga $\mathbf{J}$ and Arteaga CL: Critical update and emerging trends in epidermal growth factor receptor targeting in cancer. J Clin Oncol 23: 2445-2459, 2005.

3. Hynes NE and Lane HA: ERBB receptors and cancer: The complexity of targeted inhibitors. Nat Rev Cancer 5: 341-354, 2005

4. Wang X, Batty KM, Crowe PJ, Goldstein D and Yang JL: The potential of panHER inhibition in cancer. Front Oncol 5: 2, 2015

5. Holbro T and Hynes NE: ErbB receptors: Directing key signaling networks throughout life. Annu Rev Pharmacol Toxicol 44: 195-217, 2004.

6. Yang JL, Hannan MT, Russell PJ and Crowe PJ: Expression of HER 1/EGFR protein in human soft tissue sarcomas. Eur J Surg Oncol 32: 466-468, 2006.

7. Sato O, Wada T, Kawai A, Yamaguchi U, Makimoto A, Kokai Y, Yamashita T, Chuman H, Beppu Y, Tani Y, et al: Expression of epidermal growth factor receptor, ERBB2 and KIT in adult soft tissue sarcomas: A clinicopathologic study of 281 cases. Cancer 103: 1881-1890, 2005.

8. Teng HW, Wang HW, Chen WM, Chao TC, Hsieh YY, Hsih CH, Tzeng $\mathrm{CH}$, Chen PC and Yen CC: Prevalence and prognostic influence of genomic changes of EGFR pathway markers in synovial sarcoma. J Surg Oncol 103: 773-781, 2011.

9. Cascio MJ, O'Donnell RJ and Horvai AE: Epithelioid sarcoma expresses epidermal growth factor receptor but gene amplification and kinase domain mutations are rare. Mod Pathol 23: 574-580, 2010

10. Keizman D, Issakov J, Meller I, Maimon N, Ish-Shalom M, Sher O and Merimsky O: Expression and significance of EGFR in malignant peripheral nerve sheath tumor. J Neurooncol 94 383-388, 2009.

11. Biscuola M, Van de Vijver K, Castilla MA, Romero-Pérez L, López-García MÁ, Díaz-Martín J, Matias-Guiu X, Oliva E and Palacios Calvo J: Oncogene alterations in endometrial carcinosarcomas. Hum Pathol 44: 852-859, 2013.

12. Wang X, Goldstein D, Crowe PJ, Yang M, Garrett K, Zeps N and Yang JL: Overcoming resistance of targeted EGFR monotherapy by inhibition of STAT3 escape pathway in soft tissue sarcoma. Oncotarget 7: 21496-21509, 2016.

13. Yang JL, Gupta RD, Goldstein D and Crowe PJ: Significance of phosphorylated epidermal growth factor receptor and its signal transducers in human soft tissue sarcoma. Int J Mol Sci 18: 18, 2017.

14. Ray-Coquard I, Le Cesne A, Whelan JS, Schoffski P, Bui BN, Verweij J, Marreaud S, van Glabbeke M, Hogendoorn P and Blay JY: A phase II study of gefitinib for patients with advanced HER-1 expressing synovial sarcoma refractory to doxorubicin-containing regimens. Oncologist 13: 467-473, 2008.

15. Hawthorne VS, Huang WC, Neal CL, Tseng LM, Hung MC and Yu D: ErbB2-mediated Src and signal transducer and activator of transcription 3 activation leads to transcriptional up-regulation of p21Cip1 and chemoresistance in breast cancer cells. Mol Cancer Res 7: 592-600, 2009.
16. Proietti CJ, Rosemblit C, Beguelin W, Rivas MA, Díaz Flaqué MC, Charreau EH, Schillaci R and Elizalde PV: Activation of Stat 3 by heregulin/ErbB-2 through the co-option of progesterone receptor signaling drives breast cancer growth. Mol Cell Biol 29: 1249-1265, 2009.

17. Béguelin W, Díaz Flaqué MC, Proietti CJ, Cayrol F, Rivas MA, Tkach M, Rosemblit C, Tocci JM, Charreau EH, Schillaci R, et al: Progesterone receptor induces ErbB-2 nuclear translocation to promote breast cancer growth via a novel transcriptional effect: ErbB-2 function as a coactivator of Stat3. Mol Cell Biol 30: 5456-5472, 2010

18. Gao L, Li F, Dong B, Zhang J, Rao Y, Cong Y, Mao B and Chen X: Inhibition of STAT3 and ErbB2 suppresses tumor growth, enhances radiosensitivity, and induces mitochondriadependent apoptosis in glioma cells. Int J Radiat Oncol Biol Phys 77: 1223-1231, 2010.

19. Boyer MJ, Blackhall FH, Park K, Barrios CH, Krzakowski MJ, Taylor I, Liang JQ, Denis LJ, O'Connell JP and Ramalingam SS: Efficacy and safety of PF299804 versus erlotinib (E): A glolbal, randomized phase II trial in patients (pts) with advanced non-small cell lung cancer (NSCLC) after failure of chemotherapy (CT). In: ASCO Annual Meeting 2010. J Clin Oncol, Chicago, IL, 2010.

20. Jänne PA, Boss DS, Camidge DR, Britten CD, Engelman JA, Garon EB, Guo F, Wong S, Liang J, Letrent S, et al: Phase I dose-escalation study of the pan-HER inhibitor, PF299804, in patients with advanced malignant solid tumors. Clin Cancer Res 17: 1131-1139, 2011.

21. Engelman JA, Zejnullahu K, Gale C-M, Lifshits E, Gonzales AJ, Shimamura T, Zhao F, Vincent PW, Naumov GN, Bradner JE, et al: PF00299804, an irreversible pan-ERBB inhibitor, is effective in lung cancer models with EGFR and ERBB2 mutations that are resistant to gefitinib. Cancer Res 67: 11924-11932, 2007.

22. Gonzales AJ, Hook KE, Althaus IW, Ellis PA, Trachet E, Delaney AM, Harvey PJ, Ellis TA, Amato DM, Nelson JM, et al: Antitumor activity and pharmacokinetic properties of PF-00299804, a second-generation irreversible pan-erbB receptor tyrosine kinase inhibitor. Mol Cancer Ther 7: 1880-1889, 2008.

23. Nam H-J, Ching KA, Kan J, Kim HP, Han SW, Im SA, Kim TY, Christensen JG, Oh DY and Bang YJ: Evaluation of the antitumor effects and mechanisms of PF00299804, a pan-HER inhibitor, alone or in combination with chemotherapy or targeted agents in gastric cancer. Mol Cancer Ther 11: 439-451, 2012.

24. Takahashi T, Boku N, Murakami H, Naito T, Tsuya A, Nakamura Y, Ono A, Machida N, Yamazaki K, Watanabe J, et al: Phase I and pharmacokinetic study of dacomitinib (PF-00299804), an oral irreversible, small molecule inhibitor of human epidermal growth factor receptor-1, -2 , and -4 tyrosine kinases, in Japanese patients with advanced solid tumors. Invest New Drugs 30: 2352-2363, 2012

25. Park K, Cho BC, Kim DW, Ahn MJ, Lee SY, Gernhardt D, Taylor I, Campbell AK, Zhang H, Giri N, et al: Safety and efficacy of dacomitinib in korean patients with KRAS wild-type advanced non-small-cell lung cancer refractory to chemotherapy and erlotinib or gefitinib: A phase I/II trial. J Thorac Oncol 9: 1523-1531, 2014.

26. Reckamp KL, Giaccone G, Camidge DR, Gadgeel SM, Khuri FR, Engelman JA, Koczywas M, Rajan A, Campbell AK, Gernhardt D, et al: A phase 2 trial of dacomitinib (PF-00299804), an oral, irreversible pan-HER (human epidermal growth factor receptor) inhibitor, in patients with advanced non-small cell lung cancer after failure of prior chemotherapy and erlotinib. Cancer 120: 1145-1154, 2014.

27. Oh DY, Lee KW, Cho JY, Kang WK, Im SA, Kim JW and Bang YJ: Phase II trial of dacomitinib in patients with HER2positive gastric cancer. Gastric Cancer 19: 1095-1103, 2016.

28. Abdul Razak AR, Soulières D, Laurie SA, Hotte SJ, Singh S, Winquist E, Chia S, Le Tourneau C, Nguyen-Tan PF, Chen EX, et al: A phase II trial of dacomitinib, an oral pan-human EGF receptor (HER) inhibitor, as first-line treatment in recurrent and/or metastatic squamous-cell carcinoma of the head and neck. Ann Oncol 24: 761-769, 2013.

29. Jänne PA, Ou SH, Kim DW, Oxnard GR, Martins R, Kris MG, Dunphy F, Nishio M, O'Connell J, Paweletz C, et al: Dacomitinib as first-line treatment in patients with clinically or molecularly selected advanced non-small-cell lung cancer: A multicentre, open-label, phase 2 trial. Lancet Oncol 15: 1433-1441, 2014.

30. Kris MG, Camidge DR, Giaccone G, Hida T, Li BT, O'Connell J, Taylor I, Zhang H, Arcila ME, Goldberg Z, et al: Targeting HER2 aberrations as actionable drivers in lung cancers: Phase II trial of the pan-HER tyrosine kinase inhibitor dacomitinib in patients with HER2-mutant or amplified tumors. Ann Oncol 26: 1421-1427, 2015. 
31. Ramalingam SS, Blackhall F, Krzakowski M, Barrios $\mathrm{CH}$, Park K, Bover I, Seog Heo D, Rosell R, Talbot DC, Frank R, et al: Randomized phase II study of dacomitinib (PF-00299804), an irreversible pan-human epidermal growth factor receptor inhibitor, versus erlotinib in patients with advanced non-smallcell lung cancer. J Clin Oncol 30: 3337-3344, 2012.

32. Ellis PM, Shepherd FA, Millward M, Perrone F, Seymour L, Liu G, Sun S, Cho BC, Morabito A, Leighl NB, et al; NCIC CTG Australasian Lung Cancer Trials Group; NCI Naples Clinical Trials Unit: Dacomitinib compared with placebo in pretreated patients with advanced or metastatic non-small-cell lung cancer (NCIC CTG BR.26): A double-blind, randomised, phase 3 trial. Lancet Oncol 15: 1379-1388, 2014.

33. Ramalingam SS, Jänne PA, Mok T, O'Byrne K, Boyer MJ, Von Pawel J, Pluzanski A, Shtivelband M, Docampo LI, Bennouna $\mathrm{J}$, et al: Dacomitinib versus erlotinib in patients with advanced-stage, previously treated non-small-cell lung cancer (ARCHER 1009): A randomised, double-blind, phase 3 trial. Lancet Oncol 15: 1369-1378, 2014

34. Ramalingam SS, O'Byrne K, Boyer M, Mok T, Jänne PA, Zhang H, Liang J, Taylor I, Sbar EI and Paz-Ares L: Dacomitinib versus erlotinib in patients with EGFR-mutated advanced nonsmall-cell lung cancer (NSCLC): Pooled subset analyses from two randomized trials. Ann Oncol 27: 423-429, 2016

35. Wu YL, Cheng Y, Zhou X, Lee KH, Nakagawa K, Niho S, Tsuji F Linke R, Rosell R, Corral J, et al: Dacomitinib versus gefitinib for the first-line treatment of advanced EGFR mutation positive non-small cell lung cancer (ARCHER 1050): A randomized, open-label phase III trial. Lancet Oncol 18: 1454-1466, 2017.

36. Wang X, Goldstein D, Crowe PJ and Yang J-L: S3I-201, a Novel STAT3 Inhibitor, Inhibits Growth of Human Soft Tissue Sarcoma Cell Lines. World J Cancer Res 1: 61-68, 2013.

37. Wang X, Goldstein D, Crowe PJ and Yang JL: Impact of STAT3 inhibition on survival of osteosarcoma cell lines. Anticancer Res 34: 6537-6545, 2014.

38. Koizumi F, Shimoyama T, Taguchi F, Saijo N and Nishio K: Establishment of a human non-small cell lung cancer cell line resistant to gefitinib. Int J Cancer 116: 36-44, 2005.

39. Muller PY and Milton MN: The determination and interpretation of the therapeutic index in drug development. Nat Rev Drug Discov 11: 751-761, 2012

40. Ciardiello F and Normanno N: HER2 signaling and resistance to the anti-EGFR monoclonal antibody cetuximab: A further step toward personalized medicine for patients with colorectal cancer. Cancer Discov 1: 472-474, 2011.

41. Engelman JA, Zejnullahu K, Mitsudomi T, Song Y, Hyland C, Park JO, Lindeman N, Gale CM, Zhao X, Christensen J, et al: MET amplification leads to gefitinib resistance in lung cancer by activating ERBB3 signaling. Science 316: 1039-1043, 2007.
42. Bean J, Brennan C, Shih JY, Riely G, Viale A, Wang L, Chitale D, Motoi N, Szoke J, Broderick S, et al: MET amplification occurs with or without T790M mutations in EGFR mutant lung tumors with acquired resistance to gefitinib or erlotinib. Proc Natl Acad Sci USA 104: 20932-20937, 2007.

43. Nam H-J, Kim H-P, Yoon Y-K, Song SH, Min AR, Han SW, Im SA, Kim TY, Oh DY and Bang YJ: The irreversible pan-HER inhibitor PF00299804 alone or combined with gemcitabine has an antitumor effect in biliary tract cancer cell lines. Invest New Drugs 30: 2148-2160, 2012

44. Kalous O, Conklin D, Desai AJ, O'Brien NA, Ginther C, Anderson L, Cohen DJ, Britten CD, Taylor I, Christensen JG, et al: Dacomitinib (PF-00299804), an irreversible Pan-HER inhibitor, inhibits proliferation of HER2-amplified breast cancer cell lines resistant to trastuzumab and lapatinib. Mol Cancer Ther 11: 1978-1987, 2012.

45. Ather F, Hamidi H, Fejzo MS, Letrent S, Finn RS, Kabbinavar F, Head C and Wong SG: Dacomitinib, an irreversible Pan-ErbB inhibitor significantly abrogates growth in head and neck cancer models that exhibit low response to cetuximab. PLoS One 8: e56112, 2013.

46. Ercan D, Zejnullahu K, Yonesaka K, Xiao Y, Capelletti M, Rogers A, Lifshits E, Brown A, Lee C, Christensen JG, et al: Amplification of EGFR T790M causes resistance to an irreversible EGFR inhibitor. Oncogene 29: 2346-2356, 2010.

47. Sriuranpong V, Park JI, Amornphimoltham P, Patel V, Nelkin BD and Gutkind JS: Epidermal growth factor receptor-independent constitutive activation of STAT3 in head and neck squamous cell carcinoma is mediated by the autocrine/paracrine stimulation of the interleukin 6/gp130 cytokine system. Cancer Res 63: 2948-2956, 2003.

48. Gao SP, Mark KG, Leslie K, Pao W, Motoi N, Gerald WL, Travis WD, Bornmann W, Veach D, Clarkson B, et al: Mutations in the EGFR kinase domain mediate STAT3 activation via IL-6 production in human lung adenocarcinomas. J Clin Invest 117: 3846-3856, 2007.

49. Wang X, Crowe PJ, Goldstein D and Yang JL: STAT3 inhibition, a novel approach to enhancing targeted therapy in human cancers (Review). Int J Oncol 41: 1181-1191, 2012.

50. Kim SM, Kwon O-J, Hong YK, Kim JH, Solca F, Ha SJ, Soo RA, Christensen JG, Lee JH and Cho BC: Activation of IL-6R/JAK1/ STAT3 signaling induces de novo resistance to irreversible EGFR inhibitors in non-small cell lung cancer with T790M resistance mutation. Mol Cancer Ther 11: 2254-2264, 2012. 